\title{
Asymmetric volatility transmission between the real exchange rate and stock returns in
} South Africa

\author{
Ayanda Sikhosana ${ }^{1}$ and Goodness C. Aye ${ }^{2^{*}}$
}

\begin{abstract}
This paper analyses the asymmetric volatility spillovers between the real exchange rate and stock returns in South Africa. A Multivariate Exponential Generalized Autoregressive Conditionally Heteroskedastic (EGARCH) model alongside other asymmetric GARCH models (GJR GARCH and APARCH) were estimated using monthly data from 1996 to 2016 to examine the relationship. The results show that there is a bi-directional volatility spillover effect between the two markets in the short-run. Also these effects are asymmetric. These findings suggest that while information in one market can be used to forecast changes in the other, these financial assets should not be included in the same portfolio when diversifying risk.
\end{abstract}

JEL Classification: C58, F31, G17

Keywords: Volatility, stock market, risk, exchange rates, asymmetry

\section{Introduction}

South Africa's reintegration into the world economy resulted in substantial capital inflows from foreign investors but also increased its vulnerability to global events (Moolman and Du Toit, 2005). The Asian financial crisis during the 1990s and the 2008 global financial crisis renewed interest in the relationship between exchange rates and stock prices (Fowowe, 2015). Understanding how changes in the variance of exchange rates relate to changes in the variance of stock prices and vice versa, is important for investors when

\footnotetext{
${ }^{1}$ Department of Economics, University of Pretoria.

${ }^{2}$ Department of Economics, University of Pretoria.

* Corresponding Author's Email: goonesss.aye@gmail.com
} 
selecting an optimal investment portfolio and managing risk effectively. If volatility in one financial market spills over to another, then assets from such markets cannot be included in the same portfolio when diversifying risk (Mun, 2007).

The theoretical relationship between the foreign exchange market and the stock market is mainly explained by two models in the literature. Dornbusch and Fischer (1980) present the flow-oriented model of exchange rates which is linked to a country's current account balance. In this model, changes in the exchange rate affect the international competitiveness and profitability of firms which in turn affects stock prices. A depreciation of the domestic currency results in locally produced goods being cheaper relative to foreign goods and therefore increases exports. This increases the stock prices of exporting firms as a result of higher expected future cash flows. In contrast, an appreciation of the domestic currency results in locally produced goods being more expensive relative to foreign goods and therefore reduces foreign demand leading to a fall in stock prices. According to this model there is a positive relationship between exchange rates and stock prices with the direction of the relationship running from exchange rates to stock prices.

Branson (1983) and Frankel (1983) propose stock-oriented models of exchange rates whereby changes in the stock market lead to changes in the foreign exchange market. This occurs because changes in stock prices affect wealth which in turn affects the demand for money. An increase in stock prices leads to an increase in the demand for domestic assets (e.g. stocks and bonds) which results in increased demand for domestic currency and consequently higher interest rates. The higher interest rates attract capital inflows resulting in an appreciation of the domestic currency. In other words, such models presume that "a rise in prices encourages investors to buy more domestic assets simultaneously selling foreign assets to obtain domestic currency indispensable for buying new domestic stocks" (Stavárek, 2005). In contrast, a decrease in stock prices leads to a depreciation of the domestic currency. This suggests that there is a negative relationship between exchange rates and stock prices with the direction of the relationship running from stock prices to exchange rates. 
Existing literature indicates that the relationship between exchange rates and stock prices is dependent on the study period chosen, the frequency of data and the country being studied. In much of the literature, studies have found opposing results with regards to the short-run relationship between exchange rates and stock returns. However, these studies (Yau and Nieh 2006; Richards, Simpson, and Evans, 2009; Eita, 2012; Fowowe, 2015) focused on how changes in the mean of exchange rates affect the mean of stock prices and vice versa. The studies assume that changes in exchange rates affect stock prices symmetrically. If depreciation of the domestic currency has a positive effect on stock prices then an appreciation has the opposite effect. This is not always the case in practice. While an appreciation of domestic currency makes imported inputs cheaper, boosting profits and resulting in higher stock prices, a depreciation of domestic currency may result in some firms choosing to absorb the increased cost of imported inputs by giving up their profit margin in order to maintain market share. In this example, stock prices may not react to depreciation, suggesting that changes in exchange rates could affect stock prices asymmetrically (Bahmani-Oskooee and Saha, 2015).

There is relatively limited research on the volatility spillover effects between the exchange rate and stock markets as evidenced in the literature review section. Volatility, is the fluctuation of a variable over a period of time and the deviation from an expected value (Daly, 2008). Volatility spillover effects has implications for investors. It is critical in hedging and pricing financial instruments (Monfared and Enke, 2014). Investment decisions may be affected by financial volatility spillover effects, as investors may equate higher volatility with greater risk (Ezzati, 2013). Moreover, if two asset returns are highly correlated in terms of volatility transmission, then this reduces the possibility of portfolio diversification and hence risks reduction. From a policy perspective, volatility is also important. Of interest to policymakers is the viability of financial institutions and the smooth functioning of financial markets as these may be threatened by increasing financial volatility spillover effects (Becketti and Sellon, 1989). This will affect the type and timing of the decisions made by policy makers. Academic researchers also have great interest in volatility dynamics and spillover because the volatility process captures different dimensions of asset price dynamics (Kim and Doojin Ryu). This makes volatility modeling and forecasting an important step when studying financial time series. 
Therefore, an understanding of the origins and drivers of volatility across markets is crucial to policy makers, investors, consumers and researchers.

As far as South Africa is concerned, the few studies that exist include those of BongaBonga (2013), Kuma (2013), Oberholzer and von Boetticher (2015). These studies analysed the relationship by assuming that the spillover effects are symmetric, meaning that the effect of positive and negative volatility shocks from one market to the other are similar. However, it has been argued that a negative shock to financial time series is likely to cause volatility to rise by more than a positive shock of the same magnitude (Brooks, 2008). This study seeks to determine whether there is any relationship between the volatility in the real exchange rate and the volatility in stock returns in South Africa and whether such a relationship is symmetric or asymmetric. By so doing we will be able to determine if there is differential effect of positive shock (good news) and negative shock (bad news) with respect to volatilities spillover in the two markets. Therefore, our main contribution in this study is to examine the asymmetric relationship between exchange rate and stock returns in South Africa.

Previous testing has shown that asymmetric GARCH models outperform other GARCH family models with regard to volatility prediction (Awartani and Corradi, 2005; Alberga et al., 2008; Brownlees et al., 2011; Monfared and Enke, 2014; Berggren and Folkelid, 2014). We used the Exponential Generalized Autoregressive Conditional Heteroskedasticity (EGARCH) model developed by Nelson (1991) which is capable of capturing the asymmetry of the shocks. Moreover, with the EGARCH, there is no need to artificially impose non-negativity constraints on the model parameters as with the standard GARCH. Although EGARCH has been used by other studies such as Aloui (2007), for the U.S. and five European countries, and has been confirmed as the most successful asymmetric GARCH model for analysing volatility (Alberga et al., 2008; Bucevska, 2013), we will in addition perform a robustness check using similar asymmetric GARCH models that are also commonly used in the literature, namely the Glosten, Jangathann and Runkle (1993) GARCH (GJR-GARCH) and Ding, et al. (1993) Asymmetric Power ARCH (APARCH) models. This further strengthens the contribution of this study as the robustness analysis makes the conclusion of findings more reliable. 


\section{Literature review}

Some studies have examined volatility spillover effects between exchange rates and stock markets. For instance, Mun (2007) used weekly data from 1990 to 2003 to analyse the effect of exchange rate fluctuations on stock market volatility in eight countries compared to the US. The study also analyses the effect of exchange rate fluctuations on the correlation between the stock markets of these countries and the US. The study found that higher exchange rate fluctuations tend to increase local stock market volatility while decreasing that of the US stock market due to the stronger correlation between exchange rates and local stock market returns. Exchange rate fluctuations have a marginally negative effect on the correlation between local stock markets and the US stock market. This paper however did not consider asymmetric relationship between the two markets.

Zhao (2010) used monthly data from 1991 to 2009 to examine the relationship between the foreign exchange market and the stock market for China. VAR and multivariate Generalised Autoregressive Conditional Heteroskedasticity (GARCH) models are used to detect spillover effects between the two markets. No mean spillover effects are found between the two markets. However, bi-directional volatility spillover effects are found. Lee, Doong, and Chou (2011) used weekly data from 2000 to 2008 to examine the relationship between the two markets for East Asian countries. A bivariate Smooth Transition Conditional Correlation GARCH (STCC-GARCH) model is used to determine whether stock market volatility affects correlation between the two markets. There are significant spillover effects from the stock market to the foreign exchange market in Indonesia, Korea, Malaysia, Taiwan and Thailand. The study found that stock market volatility affects correlation between the two markets. The higher the stock market volatility, the higher the correlation between the two markets. Again Zhao (2010) and Lee et al. considered only the symmetric relationship between exchange rate and stock market volatility.

Walid et al. (2011) used weekly data and a two regime Markov Switching EGARCH model to investigate the effect of exchange rate changes on stock market volatility in four 
emerging markets: Hong Kong, Singapore, Malaysia and Mexico. Their results show evidence of regime switching behaviour in the volatility of emerging countries' stock markets. Also the relationship between exchange rates and stock prices is found to regime dependent and the volatility spillover between the two markets is asymmetric. The type of asymmetric effect considered here depends on the state of the economy, whether it is in a low or high regime. There is no explicit consideration of whether positive and negative shocks have different effects.

Liu and Tu (2011) used daily data from 2001 to 2007 to examine the relationship between stock prices, exchange rates and foreign capital markets for Taiwan. They examine how capital inflows from foreign investors affect stock market returns and how exchange rates affect foreign investor decisions to hold domestic stocks relative to international stocks. They use an asymmetric nonlinear smooth transition GARCH-M model to examine the relationship and capture both mean reversion and asymmetric volatility effects persistent in the three markets. They found that movements in stock prices and exchange rates are affected by overbuying and overselling behaviours in the foreign capital market. All three conditional means exhibit asymmetric mean-reverting behaviour, with negative returns reverting quicker than positive returns. The study also reveals that the conditional heteroskedasticity of these markets is asymmetric, generating different volatility persistence for a previous negative and positive returns shock. Aloui (2007) used an EGARCH model with daily data from 1990 to 2005 to examine the volatility spillovers between exchange rates and stock prices for five European countries and the US. The study found a significant volatility spillover effect from the stock market to the foreign exchange market for Belgium, France, Germany and Spain for the period following the introduction of the Euro (i.e., post-1999). Stock prices are less affected by exchange rate movements during the period. For all countries, negative shocks in stock prices have a more significant effect on the volatility of exchange rates after the introduction of the Euro as compared to the period before. Although Liu Aloui (2007) analysed asymmetric effect in terms of positive and negative volatility, the analysis involved five European countries and the US while Liu and Tu (2011) focused on the Taiwan economy. 
As far as South Africa is concerned, there are also some studies on volatility spillover between exchange rate and stock returns. However, none of these studies considered the asymmetric effects between these two markets. For instance, Bonga-Bonga (2013) used weekly data from 1995 to 2010 to examine the relationship between the foreign exchange market and stock market for South Africa. A generalised impulse response function obtained from a VAR model is used to examine the volatility transmission between the two markets. The study found that volatility is transmitted from the stock market to the foreign exchange market. This finding is attributed to the number of foreign investors in the South African stock market which results in large capital outflows. Transmission of volatility in the opposite direction is transitory. Kuma (2013) used both the Diebold and Yilmaz spillover VAR framework and multivariate GARCH with time varying variance-covariance BEKK model to examine the returns and volatility spillover between exchange rates and stock prices of IBSA (India, Brazil, South Africa) nations. They find bidirectional volatility spillover between stock and foreign exchange markets in the IBSA countries and that stock markets play a relatively more important role than foreign exchange markets in the first and second moment interactions and spillovers.

Oberholzer and von Boetticher (2015) used daily data from 2002 to 2014 to examine the relationship between the two markets for South Africa. A multivariate Constant Conditional Correlation GARCH (CCC-GARCH) model is used to examine the spillover effects between the markets. They found that there is a volatility spillover from the Rand to the FTSE/JSE All Share Index, Top 40 Index, Fledgling Index and the Mid Cap Index.

The empirical literature, much like the theory, shows mixed results in terms of the relationship between exchange rates and stock prices. These findings differ from country to country and may depend on the methodology and data employed. In this study we not only examine the volatility spill over between the two markets but we also investigate whether this is asymmetric. This study therefore provides a new understanding of the asymmetric relationship between South Africa's exchange rate and stock market returns.

\section{Data and methodology}


The data consist of a monthly series of the JSE All Share Index and the real Rand/US\$ exchange rate for the period January 1996 to April 2016, yielding 244 observations. Although weekly or daily data could be used as they have the advantage of providing large number of observations, however, monthly data have the advantage of limiting noise in the data relative to daily or weekly data (Dedi and Yavas, 2016; Charfeddine et al. (2018). Data on the JSE All Share Index are taken from the International Financial Statistics (IFS) published by the International Monetary Fund (IMF). The Johannesburg Stock Exchange (JSE) is among the 20 largest stock exchanges in the world with over 400 listed companies and a market capitalisation of about US\$1 trillion as of 2013 (https://www.jse.co.za). Data on the real Rand/US\$ exchange rate are calculated using the nominal Rand/US\$ exchange rate taken from the South African Reserve Bank (SARB) quarterly bulletin and adjusted by the relative consumer price indices. The consumer price index (CPI) for South Africa used to obtain the real values is taken from Statistics South Africa (StatsSA) while that of the USA is taken from the IFS.

Figure 1 shows that both the exchange rate and stock prices have experienced some degree of volatility over the period. Stock prices were increasing prior to the 2008 global financial crisis while the exchange rate had generally stabilised around R7 per US\$. During the crisis stock prices fell sharply and the exchange rate depreciated to levels around R10 per US\$. Both stock prices and the exchange rate have been generally increasing following the crisis.

Figure 1. Monthly JSE all share index and the R/US\$ exchange rate 


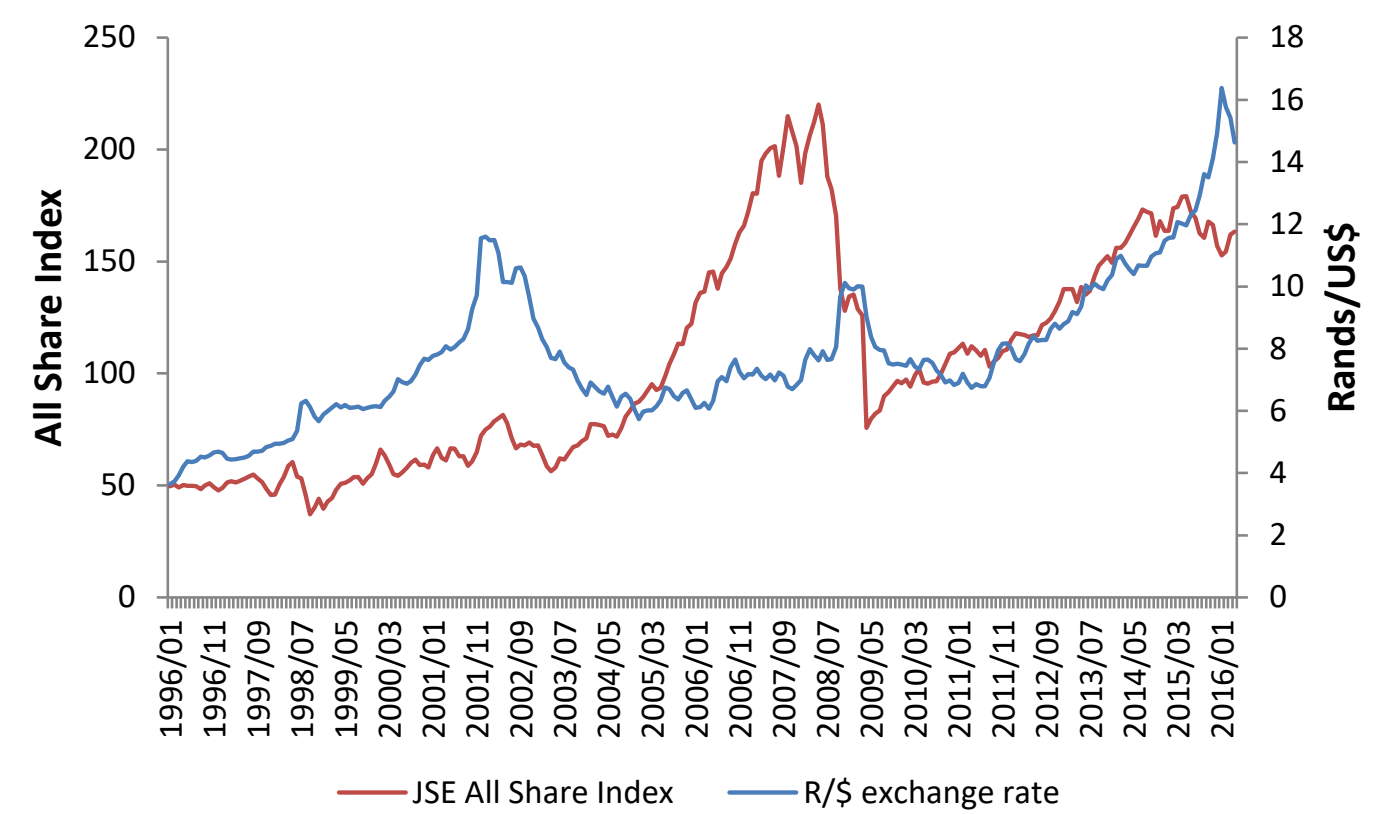

The study period is motivated by three factors. Firstly, it follows South Africa's reintegration into the world economy which increased its vulnerability to global events. Secondly, it follows the relaxation of a number of restrictive controls on foreign investors in 1995 (Moolman and Du Toit, 2005). Thirdly, the study period covers a number of financial crises including the Asian financial crisis and the more recent 2008 global financial crisis. All data were used in stationary form given the requirement of estimation of EGARCH models employed in this study.

The EGARCH model proposed by Nelson (1991) is used to examine the relationship between foreign exchange market volatility and stock market volatility. The EGARCH model has several advantages over the GARCH model which is generally used to model volatility in financial markets. Firstly, GARCH models assume that only the magnitude of stock returns determine future volatility in the returns and not whether the returns increase or decrease. However, evidence has shown that volatility tends to rise in response to bad news as opposed to good news. Secondly, GARCH models impose restrictions on the parameters which are usually violated by the estimated coefficients and which restrict the conditional variance process. Thirdly, it is difficult to interpret whether shocks to the conditional variance persist or not in GARCH models (Nelson, 1991). EGARCH models are able to capture the asymmetric volatility effects since there are no non-negative restrictions on the parameters (Walid, et al., 2011). 
The Multivariate Exponential Generalized Autoregressive Conditionally Heteroskedastic (EGARCH) conditional mean equations for the JSE All Share Index, ASI $t_{t}$ and the real Rand/US\$ exchange rate, $R_{t}$, are specified as:

$$
\begin{aligned}
& \mathrm{ASI}_{t, 0}=\alpha_{A S I, 0}+\sum_{i=1}^{n} \alpha_{A S I, \mathrm{i}} \mathrm{ASI}_{t-i}+\sum_{i=1}^{n} \alpha_{R, i} \mathrm{R}_{t-i}+\varepsilon_{A S I, t} \\
& \mathrm{R}_{t, 0}=\alpha_{R, 0}+\sum_{i=1}^{n} \alpha_{R, i} \mathrm{R}_{t-i}+\sum_{i=1}^{n} \alpha_{A S I, i} \mathrm{ASI}_{t-i}+\varepsilon_{R, t}
\end{aligned}
$$

In equations (1) and (2), $\alpha_{A S I, 0}, \alpha_{R, 0}, \alpha_{A S I, i}, \alpha_{R, i}$, for $i=1,2, \ldots, \mathrm{n}$ are parameters to be estimated and $\varepsilon_{A S I, t}$ and $\varepsilon_{R, t}$ are the error terms. The parameters measure the mean spillover effects between exchange rates and stock prices. A lag length of one is selected for both equations according to the Schwarz and Hannan-Quinn criteria. The conditional variance equations are specified as:

$$
\begin{aligned}
& \sigma^{2}{ }_{A S I, t}=\exp \left[\alpha_{A S I, 0}+\sum_{j=1}^{k} \beta_{A S I, j} \ln \left(\sigma^{2}{ }_{A S I, t-j}\right)+\theta_{A S I, A S I}\left(\left|Z_{A S I, t-1}\right|-E\left|Z_{A S I, t-1}\right|\right)+\gamma_{A S I, A S I} Z_{A S I, t-1}\right. \\
& \left.+\theta_{A S I, R}\left(\left|Z_{R, t-1}\right|-E\left|Z_{R, t-1}\right|\right)+\gamma_{A S I, R} Z_{R, t-1}\right] \\
& \sigma_{R, t}^{2}=\exp \left[\alpha_{R, 0}+\sum_{j=1}^{k} \beta_{R, j} \ln \left(\sigma_{R, t-j}^{2}\right)+\theta_{R, R}\left(\left|Z_{R, t-1}\right|-E\left|Z_{R, t-1}\right|\right)+\gamma_{R, R} Z_{R, t-1}\right. \\
& \left.+\theta_{R, A S I}\left(\left|Z_{A S I, t-1}\right|-E\left|Z_{A S I, t-1}\right|\right)+\gamma_{R, A S I} Z_{A S, t-1}\right]
\end{aligned}
$$

where $Z_{A S I}$ and $Z_{R}$ are the standardized residuals for stock returns and exchange rate changes respectively, that is $Z_{A S I, t}=\left(\varepsilon_{A S I, t} / \sigma_{A S I, t}\right)$ and $Z_{R, t}=\left(\varepsilon_{R, t} / \sigma_{R, t}\right)$. The conditional variance in one market depends on its own lag values and past values of the standardized residuals. The persistence of volatility is measured by $\beta$. The volatility spillover effect between the two markets is captured by $\theta$. If $\theta_{A S I, R}$ is statistically significant, then exchange rate volatility affects the volatility of stock prices. Asymmetric effects of one market on the other exist if $\gamma$ is statistically significant. Therefore, a positive and statistically significant $\theta$ coupled with a negative and statistically significant $\gamma$ suggest that negative shocks in one market have a greater impact on the volatility of the other market compared to positive shocks of the same magnitude. 
For robustness check we also used the GJR GARCH and APARCH models. The GJR model The GJR model is a simple extension of the standard GARCH with an additional term added to account for possible asymmetries. For simplicity, the conditional variance of the GJR GARCH is given as:

$$
\sigma_{t}^{2}=\alpha+\theta \varepsilon_{t-1}^{2}+\gamma \varepsilon_{t-1}^{2} I_{t-1}+\beta \sigma_{t-1}^{2}
$$

where $\varepsilon_{t-1}$ is the lagged residual. The indicator function, $I_{t-1}=1$ if $\varepsilon_{t-1}<0$ and 0 otherwise. If $\gamma>0$ bad news increases volatility. . If $\gamma \neq 0$ (that is, if $\gamma$ is significant) the news impact is asymmetric meaning that volatility rises more after a large negative shock than after a large positive shock. The condition for non-negativity will be $\alpha>0, \theta>0, \beta \geq 0, \theta+\gamma \geq 0$. That is, the model is still admissible, even if $\gamma<0$, provided $\theta+\gamma \geq 0$ (Brooks, 2008).

APARCH represents a general class of models that include both $A R C H$ and $G A R C H$ models. A typical APARCH conditional variance equation is given as:

$$
\sigma_{t}^{\delta}=\alpha+\sum_{i=1}^{p} \theta_{i}\left(\left|\varepsilon_{t-i}\right|-\gamma_{i} \varepsilon_{t-i}\right)^{\delta}+\sum_{j=1}^{q} \beta_{j} \sigma_{t-j}^{\delta}
$$

where $\delta>0,\left|\gamma_{i}\right|<1$ for $i=1, \ldots, r, \gamma_{i}=0$ for all $i>r$, and $r \leq p$

The symmetric model sets $\gamma_{i}=0$ for all $i$. If $\delta=2$ and $\gamma_{i}=0$ for all $i$, the PARCH model is simply a standard GARCH specification. As in the previous models, the asymmetric effects are present if $\gamma_{i} \neq 0$. A positive $\gamma_{i}$ means negative information has stronger impact than the positive information on the return volatility. In the PARCH model, the power parameter $\delta$ of the standard deviation can be estimated rather than imposed, and the optional parameters $\gamma$ are added to capture asymmetry of up to order $r$. In the empirical section we set the value of $\delta$ to be 2 while the asymmetric order is fixed to 1 similar to the rest of the models.

\section{Empirical results}


The univariate properties of all variables are evaluated using both graphical and formal unit root tests. Figure 2 shows that both stock prices and exchange rates are nonstationary in their level form but their first order differences (i.e., stock returns and exchange rate returns) are stationary. Both variables appear to be integrated of order one.

Figure 2. Visual inspection of the order of integration
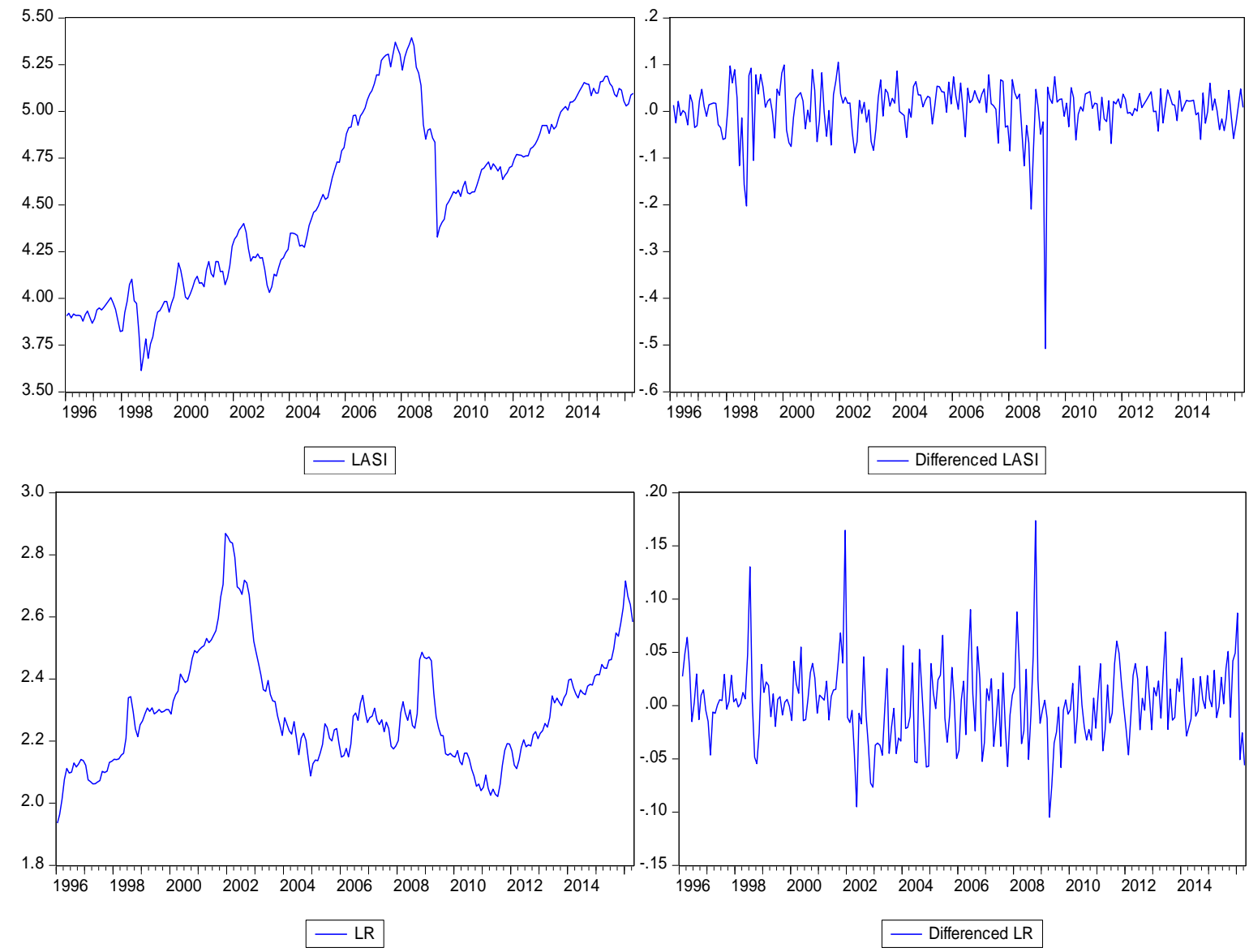

The Augmented Dickey-Fuller and the Phillips-Perron unit root tests are employed to formally test for stationarity of the variables (Dickey and Fuller, 1981; Phillips and Perron, 1988). Both Tables 1 and 2 below support the rejection of the null hypothesis of a unit root, at the $1 \%$ level of significance, for both variables in their first differenced form. This confirms that both variables are integrated of order one. 
Table 1. Augmented Dickey-Fuller unit root test

\begin{tabular}{c|ccc||ccc}
\hline \hline \multicolumn{3}{|c||}{ Level } & \multicolumn{3}{c}{ First Difference } \\
\hline Variable & $\begin{array}{c}\mathrm{t} \text {-value } \\
\text { (intercept) }\end{array}$ & $\begin{array}{c}\mathrm{t} \text {-value } \\
\text { (trend and } \\
\text { intercept) }\end{array}$ & $\begin{array}{c}\mathrm{t} \text {-value (no } \\
\text { trend no } \\
\text { intercept) }\end{array}$ & $\begin{array}{c}\mathrm{t} \text {-value } \\
\text { (intercept) }\end{array}$ & $\begin{array}{c}\mathrm{t} \text {-value } \\
\text { (trend and } \\
\text { intercept) }\end{array}$ & $\begin{array}{c}\mathrm{t} \text {-value (no } \\
\text { trend no } \\
\text { intercept) }\end{array}$ \\
\hline LASI & -1.200 & -2.081 & 0.973 & $-13.086^{* * *}$ & $-13.059^{* * *}$ & $-13.033^{* * *}$ \\
$L R$ & -2.333 & -2.325 & 0.564 & $-11.340^{* * *}$ & $-11.317^{* * *}$ & $-11.327^{* * *}$ \\
\hline \hline$(* *)[* * *$
\end{tabular}

${ }^{*}(* *)[* * *]$ indicate rejection of the null hypothesis of a unit root at a $10(5)[1] \%$ level.

Table 2. Phillips-Perron unit root test

\begin{tabular}{|c|c|c|c|c|c|c|}
\hline \multirow[b]{2}{*}{ Variable } & \multicolumn{3}{|c|}{ Level } & \multicolumn{3}{|c|}{ First Difference } \\
\hline & $\begin{array}{c}\mathrm{t} \text {-value } \\
\text { (intercept) }\end{array}$ & $\begin{array}{c}\text { t-value } \\
\text { (trend and } \\
\text { intercept) }\end{array}$ & $\begin{array}{l}\text { t-value (no } \\
\text { trend no } \\
\text { intercept) }\end{array}$ & $\begin{array}{c}\mathrm{t} \text {-value } \\
\text { (intercept) }\end{array}$ & $\begin{array}{c}\text { t-value } \\
\text { (trend and } \\
\text { intercept) }\end{array}$ & $\begin{array}{l}\text { t-value (no } \\
\text { trend no } \\
\text { intercept) }\end{array}$ \\
\hline LASI & -1.158 & -1.998 & 1.078 & $-13.034 * * *$ & $-13.006 * * *$ & $-12.986 * * *$ \\
\hline$L R$ & -2.159 & -2.150 & 0.763 & $-11.394 * * *$ & $-11.372 * * *$ & $-11.379 * * *$ \\
\hline
\end{tabular}

$*(* *)[* * *]$ indicate rejection of the null hypothesis of a unit root at a $10(5)[1] \%$ level.

Table 3 presents the estimated EGARCH model comprising of both the conditional mean and conditional variance equations relating to equations (1) and (3) above, respectively. The results show that changes in the mean of stock prices in a particular month have a statistically significant and positive effect on changes in the mean of stock prices in the following month. Consistent with the finding by Fowowe (2015), changes in the mean of stock prices do not depend on the mean exchange rate movements in the preceding month. However, the volatility of the exchange rate has a statistically significant impact on the volatility of stock prices. This finding is consistent with that of Oberholzer and von Boetticher (2015). Further, negative shocks to the exchange rate increase the volatility of stock prices more than positive shocks of the same magnitude, implying that the effect is asymmetric (Engle and Patton, 2001). In other words, 'bad news' has greater impact on volatility than 'good news'. The degree of volatility persistence can be measured by the half-life of a shock $(h)$, defined as $\beta^{h}=0.5$ (Nelson, 1991). The results show that volatility of stock prices persists for 12 months, on average.

Table 3. EGARCH estimation (stock returns) 


\begin{tabular}{crrrr}
\hline \hline Variable & Coefficient & Std. Error & z-Statistic & Prob. \\
\hline \hline \multicolumn{5}{c}{ Mean Equation } \\
\hline C & 0.006267 & 0.003075 & 2.038184 & 0.0415 \\
D_LASI(-1) & 0.135662 & 0.080366 & 1.688049 & 0.0914 \\
D_LR(-1) & -0.028116 & 0.078674 & -0.357378 & 0.7208 \\
\hline \hline \multicolumn{5}{c}{ Variance Equation } \\
\hline \hline$\alpha_{A S I, 0}$ & -0.526015 & 0.165397 & -3.180319 & 0.0015 \\
$\theta_{A S I, R}$ & 0.264113 & 0.080476 & 3.281862 & 0.0010 \\
$\gamma_{A S I, R}$ & -0.163781 & 0.054551 & -3.002353 & 0.0027 \\
$\beta_{A S I, 1}$ & 0.945273 & 0.027017 & 34.98854 & 0.0000 \\
\hline \hline
\end{tabular}

Table 4 presents the estimated EGARCH model comprising of both the conditional mean and conditional variance equations relating to equations (2) and (4) above, respectively. The results show that changes in the mean of the exchange rate in a particular month have a statistically significant and positive effect on changes in the mean of the exchange rate in the following month. Consistent with the finding by Fowowe (2015), changes in the mean of the exchange rate do not depend on the mean stock price movements in the previous month. However, the volatility of stock prices has a statistically significant impact on the volatility of exchange rates. This finding is consistent with that of BongaBonga (2013). Further, positive shocks to stock prices increase the volatility of the exchange rate more than negative shocks of the same magnitude. The results show that volatility of the exchange rate persists for 4 months, on average.

Table 4. EGARCH estimation (exchange rate returns) 


\begin{tabular}{|c|c|c|c|c|}
\hline Variable & Coefficient & Std. Error & z-Statistic & Prob. \\
\hline \multicolumn{5}{|c|}{ Mean Equation } \\
\hline$C$ & 0.004548 & 0.002297 & 1.979913 & 0.0477 \\
\hline D_LASI $(-1)$ & 0.023327 & 0.034764 & 0.670999 & 0.5022 \\
\hline$\overline{D_{-}} L \mathrm{~L}(-1)$ & 0.352026 & 0.063480 & 5.545458 & 0.0000 \\
\hline \multicolumn{5}{|c|}{ Variance Equation } \\
\hline$\alpha_{R, 0}$ & -1.238306 & 0.303002 & -4.086789 & 0.0000 \\
\hline$\theta_{R, A S I}$ & 0.355140 & 0.101993 & 3.482012 & 0.0005 \\
\hline$\gamma R, A S I$ & 0.247493 & 0.049221 & 5.028211 & 0.0000 \\
\hline$\beta_{R, 1}$ & 0.856313 & 0.043264 & 19.79267 & 0.0000 \\
\hline
\end{tabular}

As a robustness check, we report results from alternative asymmetric GARCH models, specifically, the GJR GARCH and APARCH models. These are presented in Table 5. The results are qualitatively similar with those of EGARCH in that changes in the mean of exchange rate and stock returns do not significantly affect each other but there is asymmetric volatility spillover effects between the two markets.

Table 5: Robustness with GJR GARCH and APARCH Models

\begin{tabular}{|c|c|c|c|c|c|c|c|c|}
\hline & \multicolumn{4}{|c|}{ GJR GARCH } & \multicolumn{4}{|c|}{ APARCH } \\
\hline & \multicolumn{2}{|c|}{ D_LASI } & \multicolumn{2}{|c|}{ D_LR } & \multicolumn{2}{|c|}{ D_LASI } & \multicolumn{2}{|c|}{ D_LR } \\
\hline & Coef. & Prob. & Coef. & Prob. & Coef. & Prob. & Coef. & Prob. \\
\hline & \multicolumn{8}{|c|}{ Mean Equation } \\
\hline $\mathrm{C}$ & 0.006 & 0.050 & 0.005 & 0.033 & 0.006 & 0.048 & 0.005 & 0.032 \\
\hline D_LASI(-1) & 0.166 & 0.052 & 0.009 & 0.798 & 0.166 & 0.053 & 0.009 & 0.795 \\
\hline \multirow{2}{*}{ D_LR(-1) } & -0.017 & 0.830 & 0.349 & 0.000 & -0.017 & 0.833 & 0.350 & 0.000 \\
\hline & \multicolumn{8}{|c|}{ Variance Equation } \\
\hline$\alpha$ & 0.000 & 0.049 & 0.000 & 0.009 & 0.000 & 0.049 & 0.000 & 0.009 \\
\hline$\theta$ & 0.078 & 0.204 & 0.565 & 0.000 & 0.203 & 0.006 & 0.230 & 0.033 \\
\hline$\gamma$ & 0.308 & 0.013 & -0.521 & 0.000 & 0.376 & 0.022 & -0.570 & 0.052 \\
\hline$\beta$ & 0.756 & 0.000 & 0.637 & 0.000 & 0.756 & 0.000 & 0.638 & 0.000 \\
\hline
\end{tabular}

\section{v. Conclusion}

The results of the study indicate that there is a bi-directional volatility spillover effect between the two markets in the short-run. Negative shocks in the exchange rate market have a greater impact on volatility in the stock market while positive shocks in the stock 
market have a greater impact in transmitting volatility to the exchange rate market. These findings suggest that lagged information from one market can be used to forecast changes in the other market, with a longer forecast horizon for the stock market as compared to the exchange rate market. Furthermore, these findings also suggest that portfolio managers should not include stocks and currency in the same asset portfolio when trying to diversify risk. Possible areas for future research could include studying the volatility transmission between the two markets controlling for other variables such as inflation, interest rates, money supply and GDP and also considering possible structural breaks in the data.

\section{References}

Alberga, D., Shalita, H. and Yosef, R. (2008). Estimating stock market volatility using asymmetric GARCH models. Applied Financial Economics, 18, 1201-1208.

Aloui, C. (2007). Price and volatility spillovers between exchange rates and stock indexes for the pre- and post-euro period. Quantitative Finance, 7, 669-685.

Awartani, B. M. A, and Corradi, V. (2005) Predicting the volatility of the S\&P-500 stock index via GARCH models: the role of asymmetries. International Journal of Forecasting, 21, 167-183.

Bahmani-Oskooee, M., and Saha, S. (2015). On the relation between stock prices and exchange rates: a review article. Journal of Economic Studies, 42, 707-732.

Becketti, S. and Sellon Jr., G.H. (1989) Has Financial Market Volatility Increased? Economic Review, pp. 17-30.

Bonga-Bonga, L. (2013). Transmission of volatility shocks between the equity and foreign exchange markets in South Africa. Journal of Applied Business Research, 29, 1529-1540. 
Branson, W.H. (1983). Macroeconomic determinants of real exchange risk. In R.J.

Herring (Ed.), Managing foreign exchange risk (pp. 33-74). Cambridge, Cambridge University Press.

Brooks, C. (2008). Introductory Econometrics for Finance. Second Edition. Cambridge University Press, New York, United States.

Brownlees, C., Engle, R. and Kelly, B.(2011). A practical guide to volatility forecasting through calm and storm. The Journal of Risk , 14(2), 3-22.

Bucevska V. (2013) An Empirical Evaluation of GARCH Models in Value-at-Risk Estimation: Evidence from the Macedonian Stock Exchange. Business System Research, 4(1), 49-64.

Charfeddine, L., Khediri, K.B., Aye, G.C. and Gupta, R. (2018) Time-varying efficiency of developed and emerging bond markets: Evidence from long-spans of historical data. Physica A, 505, 632-647.

Daly, K. (2008). Financial volatility: Issues and measuring techniques. Physica A: Statistical Mechanics and its Applications, 387(11):2377-2393.

Dedi, L. and Yavas, B.F. (2016). Return and volatility spillovers in equity markets: An investigation using various GARCH methodologies, Cogent Econ. Finance 4, 1-18.

Dickey, D.A., and Fuller, W.A. (1981). Likelihood ratio statistics for autoregressive time series with a unit root. Econometrica, 49, 1057-1072.

Dornbusch, R., and Fischer, S. (1980). Exchange rates and the current account. American Economic Review, 70, 960-971. 
Eita, J.H. (2012). Modelling macroeconomic determinants of stock market prices: evidence from Namibia. Journal of Applied Business Research, 28, 871-884.

Engle, R.F., and Patton, A.J. (2001). What good is a volatility model?. Quantitative Finance, 1, 237-245.

Ezzati, P. (2013). Analysis of volatility spillover effects: Two-stage procedure based on a modified GARCH-M, University of Western Australia, Discussion Paper (13.29), 1-33.

Fowowe, B. (2015). The relationship between stock prices and exchange rates in South Africa and Nigeria: structural breaks analysis. International Review of Applied Economics, 29, 1-14.

Frankel, J.A. (1983). Monetary and portfolio-balance models of exchange rate determination. In J. Bhandari and B. Putnam (Eds.), Economic interdependence and flexible exchange rates (pp. 84-115). Cambridge, MIT Press.

Kim, J.S. and Ryu, D. (2015). Return and volatility spillovers and cojump behavior between the U.S. and Korean stock markets, Emerging Markets Finance and Trade, 51:sup1, S3-S17.

Kumar M (2013). Returns and volatility spillover between stock prices and exchange rates: Empirical evidence from IBSA countries. International Journal of Emerging Markets, 8(2), 108-128.

Lee, C.H., Doong, S.C., and Chou, P.I. (2011). Dynamic correlation between stock prices and exchange rates. Applied Financial Economics, 21, 789-800.

Liu, H.H., and Tu, T.T. (2011). Mean-reverting and asymmetric volatility switching 
properties of stock price index, exchange rate and foreign capital in Taiwan. Asian Economic Journal, 25, 375-395.

Monfared, S.A. and Enke, D. (2014) Volatility Forecasting using a Hybrid GJR-GARCH Neural Network Model. Procedia Computer Science, 36, 246 - 253.

Moolman, E., and Du Toit, C. (2005). An econometric model of the South African stock market. South African Journal of Economic and Management Sciences, 8, 77-91.

Mun, K.C. (2007). Volatility and correlation in international stock markets and the role of exchange rate fluctuations. Journal of International Financial Markets, Institutions and Money, 17, 25-41.

Nelson, D.B. (1991). Conditional heteroskedasticity in asset returns: a new approach. Econometrica, 59, 347-370.

Oberholzer, N., and von Boetticher, S.T. (2015). Volatility spill-over between the JSE/FTSE indices and the South African Rand. Procedia Economics and Finance, 24, 501-510.

Phillips, P.C.B., and Perron, P. (1988). Testing for a unit root in time series regression. Biometrika, 75, 335-346.

Richards, N.D., Simpson, J., and Evans, J. (2009). The interaction between exchange rates and stock prices: an Australian context. International Journal of Economics and Finance, 1, 3-23.

Stavárek, D. (2005). Stock Prices and exchange rates in the EU and the USA: evidence of their mutual. Finance a úvûr -Czech Journal of Economics and Finance, 55, 141-161.

Walid, C., Aloui, C., Masood, O., and Fry, J. (2011). Stock market volatility and exchange 
rates in emerging countries: a Markov-state switching approach, Emerging Markets Review, 12, 272-292.

Yau, H.Y., and Nieh, C.C. (2006). Interrelationships among stock prices of Taiwan and Japan and NTD/yen exchange rate. Journal of Asian Economics, 17, 535-552.

Zhao, H. (2010). Dynamic relationship between exchange rate and stock price: evidence from China. Research in International Business and Finance, 24, 103-112. 